\title{
Relation of Vaspin and Visfatin Levels with the Presence and the Severity of Coronary Artery Disease
}

\author{
Sahar EM El-Deek ${ }^{1}$, Mohamed Aboel-Kassem F Abdelmegid ${ }^{2, *}$, Mona M Soliman ${ }^{3}$ \\ Amr A Youssef ${ }^{2}$ \\ ${ }^{1}$ Medical Biochemistry Department, Faculty of Medicine, Assiut University, Assiut, Egypt \\ ${ }^{2}$ Cardiovascular Medicine Department, Faculty of Medicine, Assiut University, Assiut, Egypt \\ ${ }^{3}$ Internal Medicine Department, Faculty of Medicine, Assiut University, Assiut, Egypt \\ *Corresponding Author: aboelkassem1970@yahoo.com
}

Copyright (C 2014 Horizon Research Publishing All rights reserved.

\begin{abstract}
Background: Adipocytokines may play role in pathogenesis of atherosclerosis. The association of the novel adipocytokines, vaspin and visfatin, with atherosclerosis coronary artery disease (CAD) is still obscure. Objectives: To investigate the relationship of vaspin and visfatin adipocytokines with the existence as well as the severity of CAD. Patients and Methods: A total of 87 patients who underwent coronary angiography due to symptoms of stable angina were enrolled in the study. They were divided into two groups; CAD group who have at least single vessel disease and normal group who have normal coronary arteries. The severity of CAD was assessed using coronary angiography by estimation the number of vessels affected and Gensini score. Results: Serum levels of vaspin were significantly lower and inversely, serum levels of visfatin were significantly higher in CAD group than normal (1.51 \pm $0.99 \mu \mathrm{g} / \mathrm{L}$ versus $4.54 \pm 0.69 \mu \mathrm{g} / \mathrm{L}$ for the former and $22.86 \pm$ $4.68 \mu \mathrm{g} / \mathrm{L}$ versus $13.43 \pm 1.1 \mu \mathrm{g} / \mathrm{L}$ for the later; $\mathrm{p}<0.0001$ for each). Decreased vaspin and increased visfatin levels were correlated with CAD severity ( $<<0.0001$ for each). There was a negative correlation between vaspin and the Gensini score and positive correlation between visfatin and Gensini score $(r=-0.727, p<0.00001$ and $r=0.798, p<0.00001$, respectively). Conclusion: Patients with CAD showed reduced vaspin and increased visfatin serum levels. Moreover, low vaspin and high visfatin levels were significantly correlated with CAD severity suggesting a link between atherosclerosis and adiposity.
\end{abstract}

Keywords Vaspin, Visfatin, Coronary Artery Disease

\section{Introduction}

Coronary artery disease (CAD) remain the principal and the major cause morbidity and mortality burden worldwide [1]. Obesity, as expressed by adipose tissue accumulation, constitutes a worldwide epidemic; roughly 500 million adults are obese (defined as a body mass index, of $30 \mathrm{~kg} / \mathrm{m}^{2}$ or higher) that's almost $10 \%$ of men and $14 \%$ of women [2] and independent risk factor for CAD [3]. Intra-abdominal (visceral) adipose tissue in particular, rather than peripheral, appears to be associated with global cardio-metabolic risk [4]. Adipose tissue, besides its role as an energy storing organ, shows endocrine properties especially in systemic vascular inflammation [5]. Various pro- and anti-inflammatory mediators and cytokines are secreted from adipose tissue are collectively called adipocytokines. It has been demonstrated that adipocytokines regulate different stages of atherosclerosis, from endothelial dysfunction to plaque destabilization and rupture [6,7].

Visfatin is a novel adipocytokine which mainly found in visceral adipose tissue and mimics insulin in lowering plasma glucose levels [8]. Visfatin has been shown that may have a role in plaque destabilization, the promotion of angiogenesis, and glucose homeostasis, so it may have a role in atherosclerosis and coronary artery disease [9]. Moreover, Wang et al. [10] reported that, visfatin participates in several pathophysiological processes contributing to cardio-cerebro-vascular diseases, including hypertension, atherosclerosis, ischemic heart disease.

Vaspin is another newly member of adipocytokines which originally identified in visceral white adipose tissues [11]. It has anti-inflammatory and anti-apoptotic effects on vascular cells as well as improving insulin resistance. Vaspin could inhibit inflammatory factor secretion from vascular smooth muscle cells and antagonize endothelial cell apoptosis induced by free fatty acid $[12,13]$. Therefore, its deficiency may play an important role in development of atherosclerosis. However, the relationship between vaspin and visfatin and CAD has not been adequately studied.

\section{Aim of the Work}

To investigate the association of serum vaspin and visfatin 
levels with the presence of $\mathrm{CAD}$ and detect its role for early diagnosis of this disease. Moreover, to evaluate the correlation between vaspin and visfatin with the severity of $\mathrm{CAD}$ assessed by number of vessels affected and validated angiographic Gensini score.

\section{Patients and Methods}

\subsection{Patients}

This cross-sectional study was conducted on 87 consecutive patients who underwent coronary angiography due to symptoms of stable angina at Cardiology department, Faculty of Medicine, Assiut University. Stable angina defined as the presence of chest pain that did not change its pattern during the preceding 2 month. For all patients, cardiovascular history was taken, complete physical examination was performed and electrocardiogram and echocardiography were done then any abnormalities were recorded. Patients with history of acute coronary syndrome within the past 6 months, severe chronic heart failure (class NYHA III-IV), cardiomyopathy, diabetes mellitus, morbid obesity (BMI $>35$ ), history of revascularization, malignant disease, major trauma or surgery, severe renal (creatinine $>2$ $\mathrm{mg} / \mathrm{dl}$ ) or liver insufficiency (ALT $>2$ times upper normal limit), acute or chronic infectious disease, or any kind of immune-mediated disease were excluded from the study.

The study was approved by the ethical committee of faculty of medicine, Assiut University. All patients were informed about the study, and their written consent forms were obtained.

\subsection{Methods}

\subsubsection{Biochemical Measurement}

After an overnight fasting, $10 \mathrm{ml}$ venous blood samples were withdrawn from the antecubital vein under complete aseptic condition before coronary angiography. The collected blood samples were centrifuged then the separated serums were stored at $-70^{\circ} \mathrm{C}$ until measurement of biochemical parameters. Vaspin and visfatin were measured by an ELISA kit for quantitative determination (GLORY Science, Del Rio, USA and WKEA MED SUPPLIES, New York, USA, respectively). Total cholesterol, triglyceride, high density lipoprotein cholesterol (HDL-C) and low density lipoprotein cholesterol (LDL-C) were assayed by the enzymatic colorimetric method using Roche/Hitachi/911 automated Clinical Chemistry Analyzer. The Kit manufactured by Roche Diagnostics gmbh, D-68298 Mannheim, USA. Routine determination of random blood glucose and creatinine were performed.

\subsubsection{Coronary Angiography}

Coronary angiography was performed to all subjects through radial or femoral artery approach. Significant CAD was defined as at least one major coronary artery having $\geq 70 \%$ or left main coronary artery $\geq 50 \%$ luminal diameter stenosis [14]. Accordingly, the study population was classified into two groups; CAD group consisted of 56 patients who have CAD and the normal group consisted of 31 patients who have normal coronary anatomy.

The CAD group was sub-classified according to the severity of CAD by counting number of diseased vessels as 1-, 2- or 3-vessel disease. The left main coronary artery stenosis $\geq 50 \%$ was considered as a 2 -vessel disease.

The severity of CAD was assessed by angiographic Gensini score [15]. Gensini score based on degree of luminal narrowing multiplied for specific coronary tree locations then the total of the lesion scores is summed to give a final Gensini score. Briefly, Gensini score was calculated as follow: it grades the narrowing of the lumen of the coronary artery as; 1 for $\leq 25 \%$ narrowing, 2 for $26-50 \%$ narrowing, 4 for $51-75 \%$ narrowing, 8 for $76-90 \%$ narrowing, 16 for $91-99 \%$ narrowing, and 32 for total occlusion. Next, this primary score is multiplied by a factor that takes into account the importance of the position of the lesion in the coronary arterial tree. Five for the left main coronary, 2.5 for proximal left anterior descending artery or proximal left circumflex artery and 1.5 for mid-region, 1 for the distal left anterior descending artery and 1 for mid-distal region of the left circumflex artery or right coronary artery. Gensini score was expressed as the sum of the scores for all three coronary arteries to evaluate the entire extent of coronary artery disease. An experienced cardiologist, unaware of the biochemical results of the patients, visually reviewed all angiographic images to assess the extent of CAD.

\subsection{Statistical Analysis}

Continuous variables were presented as mean $\pm \mathrm{SD}$, and categorical data were defined as frequencies and percentages. For Continuous variables, comparisons between two groups were carried out using an unpaired student's t-test for normally distributed data and Mann-Whitney test for non-normally distributed data. Categorical variables were compared using Chi-Square test or Fisher exact test when appropriate. The one-way ANOVA was used to determine the significance of the difference between the groups. Correlation analysis was performed using the Pearson coefficient of correlation. $\mathrm{P}$ value $<0.05$ will consider significant. SPSS for windows software was used for statistical analysis (Version 16, SPSS Inc., Chicago, IL, USA).

\section{Results}

The study population was classified according to the presence of significant CAD into two groups; CAD group (56 patients, 64.4\%) and normal group (31 patients, 35.6\%). The baseline clinical characteristics and biochemical parameters of the study groups were presented in table 1 . The 
CAD group patients were significantly older, smoker and more frequently having hyperlipidemia than normal group $(p=0.001,0.001$ and 0.01 , respectively). The levels of total cholesterol, triglycerides, LDL-C were significantly higher in CAD group than normal group $(\mathrm{P}=0.002,<0.0001$ and $<0.0001$, respectively). On the other hand, HDL-C was significantly lower in $\mathrm{CAD}$ group than normal group $(\mathrm{p}<0.0001)$.

Table 1 shows that the serum level of vaspin was significantly lower in CAD group than normal group (1.51 \pm $0.99 \mu \mathrm{g} / \mathrm{L}$ and $4.54 \pm 0.69 \mu \mathrm{g} / \mathrm{L}$, respectively, $\mathrm{p}<0.0001)$. In contrast, the serum level of visfatin was significantly higher in CAD group compared with normal group $(22.86 \pm 4.68$ $\mu \mathrm{g} / \mathrm{L}$ versus $13.43 \pm 1.1 \mu \mathrm{g} / \mathrm{L}$, respectively, $\mathrm{p}<0.0001)$.

The CAD group was sub-classified according to number of diseased coronary arteries into 1 vessel (21 patients), 2 vessels (20 patients) and 3 vessels (15 patients) group. It was clear that the serum level of vaspin was significantly lower (Figure $1 \mathrm{~A}$ ) and serum level visfatin was significantly higher (Figure 1 B) in groups with more vessels involvement (Table 2). In addition, a negative correlation between vaspin and the Gensini score was reported $(r=-0.727, p<0.00001$ and Figure $2 \mathrm{~A}$ ). On the contrary, there was a positive correlation between visfatin and Gensini score $(r=0.798, p<$ 0.00001 respectively and Figure 2 B).

Table 1. Clinical and biochemical characteristics of the study population by the presence of CAD

\begin{tabular}{|c|c|c|c|}
\hline Patient characteristics & $\begin{array}{c}\text { Normal group } \\
(\mathrm{n}=31)\end{array}$ & $\begin{array}{l}\text { CAD group } \\
(\mathrm{n}=56)\end{array}$ & $P$ value \\
\hline Age (years) & $49.9 \pm 6.3$ & $56.3 \pm 8.7$ & 0.001 \\
\hline Male, n (\%) & $13(61.9 \%)$ & $38(67.9 \%)$ & 0.13 \\
\hline Smoking, n (\%) & $5(16.1 \%)$ & $30(53.6 \%)$ & 0.001 \\
\hline Hypertension, n (\%) & $17(54.8 \%)$ & $24(42.9 \%)$ & 0.28 \\
\hline Hyperlipidemia, n (\%) & $7(22.6 \%)$ & $28(50 \%)$ & 0.01 \\
\hline LVEF (\%) & $59.4 \pm 7.3$ & $57.2 \pm 7.7$ & 0.19 \\
\hline RBG (mg/dl) & $107.0 \pm 19.1$ & $115.0 \pm 27.3$ & 0.15 \\
\hline Creatinine $(\mu \mathrm{mol} / \mathrm{dl})$ & $67.9 \pm 11.4$ & $78.2 \pm 22.0$ & 0.01 \\
\hline $\mathrm{TC}(\mathrm{mg} / \mathrm{dl})$ & $212.4 \pm 21.9$ & $233.9 \pm 36.9$ & 0.002 \\
\hline $\mathrm{TG}(\mathrm{mg} / \mathrm{dl})$ & $143.4 \pm 29.4$ & $201.6 \pm 43.3$ & $<0.0001$ \\
\hline LDL-C (mg/dl) & $128.0 \pm 17.5$ & $160.1 \pm 38.1$ & $<0.0001$ \\
\hline HDL-C (mg/dl) & $47.4 \pm 9.0$ & $32.6 \pm 7.5$ & $<0.0001$ \\
\hline Gensini score & $0.3 \pm 1.1$ & $54.2 \pm 42.2$ & $<0.0001$ \\
\hline Vaspin $(\mu \mathrm{g} / \mathrm{L})$ & $4.54 \pm 0.69$ & $1.51 \pm 0.99$ & $<0.0001$ \\
\hline Visfatin $(\mu \mathrm{g} / \mathrm{L})$ & $13.43 \pm 1.10$ & $22.86 \pm 4.68$ & $<0.0001$ \\
\hline
\end{tabular}

CAD, coronary artery disease; HDL-C, high density lipoprotein cholesterol; LDL-C, low density lipoprotein cholesterol; LVEF, left ventricular ejection fraction; RBG, random blood glucose; TC, total cholesterol; TG, total triglyceride. 
Table 2. Clinical and biochemical characteristics of the study population by the number of affected coronary artery.

\begin{tabular}{|c|c|c|c|c|c|}
\hline Patient characteristics & $\begin{array}{l}\text { Normal } \\
(\mathrm{n}=31)\end{array}$ & $\begin{array}{c}1 \text { vessel CAD } \\
(\mathrm{n}=21)\end{array}$ & $\begin{array}{c}2 \text { vessels CAD } \\
(\mathrm{n}=20)\end{array}$ & $\begin{array}{c}3 \text { vessels CAD } \\
(\mathrm{n}=15)\end{array}$ & $P$ value \\
\hline Age (years) & $49.9 \pm 6.3$ & $51.7 \pm 8.7$ & $58.5 \pm 6.4$ & $60.0 \pm 8.9$ & $<0.0001$ \\
\hline Male, n (\%) & $13(61.9 \%)$ & $13(61.9 \%)$ & $15(66.7 \%)$ & $10(51.6 \%)$ & 0.39 \\
\hline Smoking, n (\%) & $5(16.1 \%)$ & $10(47.6 \%)$ & $12(60.0 \%)$ & $8(53.3 .7 \%)$ & 0.006 \\
\hline Hypertension, n (\%) & $17(54.8 \%)$ & $10(47.6 \%)$ & $7(35.0 \%)$ & $7(46.7 \%)$ & 0.58 \\
\hline Hyperlipidemia, n (\%) & $7(22.6 \%)$ & $4(19.0 \%)$ & $12(60.0 \%)$ & $12(80.0 \%)$ & 0.0001 \\
\hline LVEF (\%) & $59.4 \pm 7.3$ & $56.4 \pm 6.6$ & $56.9 \pm 8.7$ & $58.6 \pm 8.3$ & 0.49 \\
\hline $\mathrm{RBG}(\mathrm{mg} / \mathrm{dl})$ & $107.0 \pm 19.1$ & $108.4 \pm 28.3$ & $117.0 \pm 21.9$ & $121.5 \pm 31.8$ & 0.19 \\
\hline Creatinine $(\mu \mathrm{mol} / \mathrm{dl})$ & $67.9 \pm 11.4$ & $74.8 \pm 15.5$ & $84.2 \pm 31.2$ & $75.0 \pm 13.3$ & 0.03 \\
\hline $\mathrm{TC}(\mathrm{mg} / \mathrm{dl})$ & $212.4 \pm 21.9$ & $223.6 \pm 28.1$ & $234.0 \pm 35.0$ & $246.1 \pm 46.3$ & 0.01 \\
\hline $\mathrm{TG}(\mathrm{mg} / \mathrm{dl})$ & $143.4 \pm 29.4$ & $189.5 \pm 30.5$ & $208.1 \pm 56.1$ & $207.6 \pm 35.7$ & $<0.0001$ \\
\hline LDL-C (mg/dl) & $128.0 \pm 17.5$ & $138.9 \pm 21.9$ & $150.0 \pm 32.4$ & $199.2 \pm 32.3$ & $<0.0001$ \\
\hline HDL-C (mg/dl) & $47.4 \pm 9.0$ & $36.6 \pm 6.5$ & $30.9 \pm 9.4$ & $30.0 \pm 2.9$ & $<0.0001$ \\
\hline Gensini score & $0.3 \pm 1.1$ & $30.0 \pm 18.4$ & $41.0 \pm 23.8$ & $105.6 \pm 42.3$ & $<0.0001$ \\
\hline Vaspin $(\mu \mathrm{g} / \mathrm{L})$ & $4.54 \pm 0.69$ & $2.61 \pm 0.63$ & $1.15 \pm 0.29$ & $0.46 \pm 0.13$ & $<0.0001$ \\
\hline Visfatin $(\mu \mathrm{g} / \mathrm{L})$ & $13.43 \pm 1.10$ & $17.60 \pm 1.15$ & $23.83 \pm 1.04$ & $28.94 \pm 0.66$ & $<0.0001$ \\
\hline
\end{tabular}

A

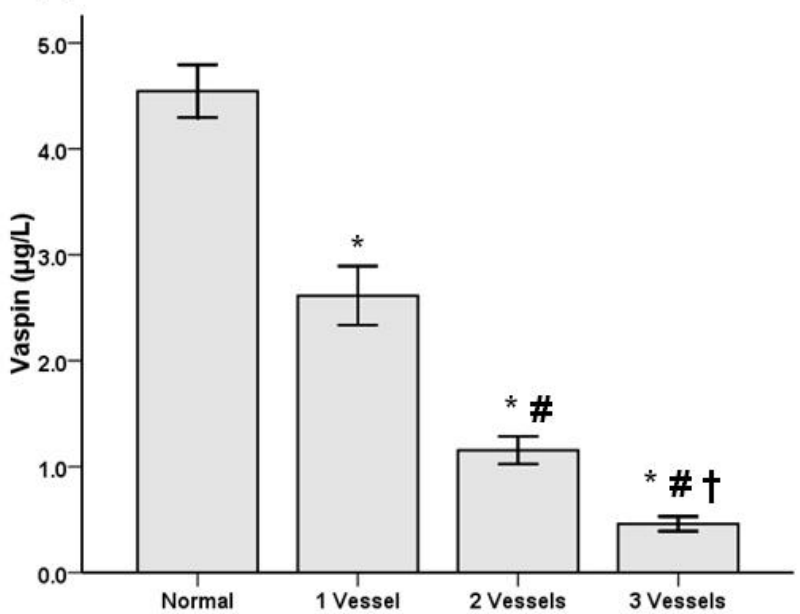

B

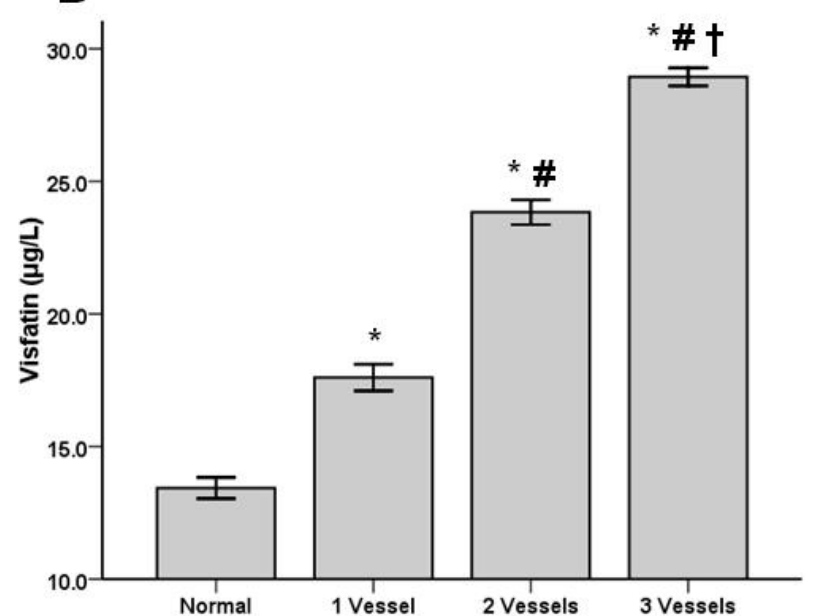

Figure 1. Differences between number of diseased coronary artery and serum vaspin (A) \& visfatin (B). $* p<0.0001$ for differences between normal coronary artery group and other groups; $\# \mathrm{p}<0.0001$ for differences between 1 vessel coronary artery disease group and other groups; $\uparrow \mathrm{p}<0.0001$ for differences between 2 vessels coronary artery disease group and other groups. 

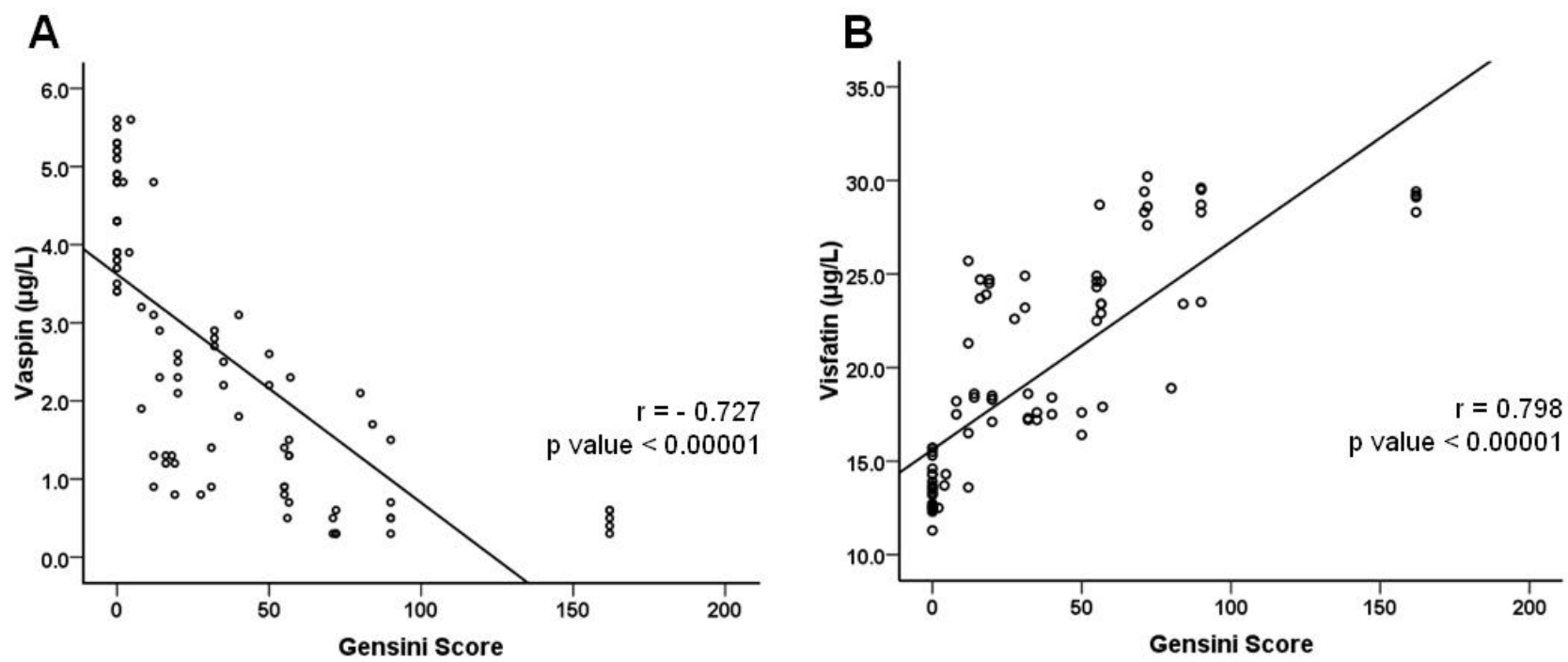

Figure 2. Correlation between Gensini score and serum vaspin (A) \& visfatin (B).

\section{Discussion}

Adipose tissue synthesis many bioactive substances participating into the circulation such as vaspin, visfatin, leptin, adiponectin, resistin that influence atherosclerosis, inflammation, insulin resistance and diabetes $[16,17]$. Vaspin and visfatin have been identified as interesting novel adipocytokines secreted from visceral adipose tissue and having insulin-sensitizing and insulin-mimetic effects, respectively [18]. However, the association of these adipocytokines with atherosclerosis is still obscure.

In the present study, reduced vaspin and increased visfatin serum levels was observed in patients with stable CAD in comparison with normal coronary arteries patients. Furthermore, the presence of CAD showed significant correlation with vaspin (negative) and visfatin (positive) serum levels. Moreover, there was a negative correlation between serum vaspin levels and CAD severity as expressed by number of significantly narrowed coronary arteries and Gensini score. Patients with morbid obesity, diabetes mellitus, metabolic syndrome, heart failure, previous CAD history, which might affect the vaspin and visfatin levels, were excluded.

In agreement with our results, Kadoglou et al. [19] showed decreased vaspin serum levels in asymptomatic patients with CAD compared with healthy control subjects. Moreover, they observed that low circulating vaspin concentrations were significantly correlated with CAD severity. In their study, the absence of CAD in the healthy group was based on clinical criteria and non-invasive imaging methods (e.g. electrocardiography and echocardiography). However, in our study, the absence of CAD in the healthy group was based on angiographically normal coronary anatomy. In addition, Kobat et al. [20] found that, serum vaspin levels significantly lower in patients with CAD than age- and sex-matched subjects with normal coronary anatomy which consistent with our result and it may be used as a predictor of this disease. This was the first study demonstrating low serum vaspin levels in CAD comparing to the age- and sex-matched subjects with normal coronary anatomy. Accordingly, they thought that this biomarker may have a protective role for CAD. However, they did not define the correlation of vaspin and the presence of $\mathrm{CAD}$ and its relation to the severity of CAD. In our study, we observed a negative correlation of vaspin with the presence and severity of CAD. Moreover, Li et al. [21] studied vaspin plasma concentration and mRNA expressions in patients with stable and unstable angina pectoris. They found decreased vaspin levels and mRNA expression of vaspin in peripheral blood mononuclear cells in patients with unstable angina. Low vaspin concentrations correlate with CAD severity. These findings suggested that vaspin could serve as a novel biomarker of CAD. In patients with acute coronary syndrome, Zhang et al. [22] found that plasma vaspin concentration is decreased, but unchanged in healthy controlled patients and those without significant coronary lesions. They added that, plasma vaspin correlated to the severity of CAD. Furthermore, they suggested that plasma vaspin may have a value of avoiding patients without $C A D$ from unnecessary coronary angiography. Moreover, Li et al. [23] studied the association of vaspin gene polymorphisms with CAD in Chinese population. Their results showed that the variants of vaspin gene are associated with serum vaspin levels and risk for CAD. On the other hand, Aust et al. [16] could not found any relation between serum vaspin levels and carotid artery atherosclerosis severity but they demonstrated that lower serum levels had correlation with recent ischemic events in patients with carotid artery stenosis.

On the basis of the present study, the exact mechanisms under the relationship between decreased vaspin level and atherosclerosis cannot be established but several explanations should be considered. Firstly, vaspin is a novel adipocytokine that had anti-inflammatory effects on vascular smooth muscle cells (SMCs). SMCs migration is an important process for development of atherosclerosis [24]. In 
vitro study, vaspin significantly inhibited platelet-derived growth factor-BB-induced SMCs migration through inhibiting phosphorylation of $\mathrm{P} 38$ and heat shock protein 27 as well as reactive oxygen generation [25]. In addition, vaspin inhibited platelet-derived growth factor-BB-induced actin cytoskeletal reorganization which is essential for SMCs migration [25]. Secondly, vaspin may be important in modifying several recognized cardiovascular risk factors. Animal experiment showed administration of vaspin to obese mice improved glucose tolerance [11].

In the present study, patients with stable CAD had increased visfatin levels compared with normal coronary arteries patients. Also, there was a positive correlation between serum visfatin levels and CAD severity as expressed by number of significantly narrowed coronary arteries and Gensini score.

In agreement with our result, $\mathrm{Fu}$ et al. [26] found that, plasma visfatin level was significantly higher in CAD group than that in control group. Also a significant positive correlation was found between coronary lesion severity score and plasma visfatin level. They concluded that plasma visfatin level may be related to the pathogenesis of CAD and detection of this adipocytokine might be helpful for early diagnosis of CAD and higher level indicate more severe coronary lesion. In addition, Liu et al. [27] found that, plasma visfatin levels were significantly higher in chronic $\mathrm{CAD}$ and acute coronary syndromes compared with control patients. Besides, its concentrations were found to be independently associated with the presence of CAD after adjustment for other well-known CAD risk factors. Therefore, they suggest that visfatin may be one of the clinically important proteins associated with inflammation, atherosclerosis, and, especially, acute coronary syndromes. Moreover, Mazaherioun et al. [7] demonstrated that high levels in patients with acute myocardial infarction and had a sensitivity of $70 \%$ and a specificity of $75 \%$ for predicting acute myocardial infarction concluded that, visfatin play a role in the development of atherosclerosis as well as destabilization of the plaque. Kadoglou et al. [19] studied the serum levels of both vaspin and visfatin in patients with CAD. They found that serum visfatin was significantly related to $\mathrm{CAD}$ existence, but not with angiographical indexes of coronary atherosclerosis severity.

In vitro study, visfatin at doses measurable in acute coronary syndrome patient plasma, induces transcription of tissue factor mRNA and promoting tissue factor expression. Increase surface expression of tissue factor induces a procoagulant phenotype in human coronary endothelial cells [28]. This observations support the hypothesis that this adipocytokine might play a relevant role as an active partaker in athero-thrombotic disease. In addition, Filippatos et al. [29] showed a significant association between visfatin plasma concentration and anthropometric, lipid, and carbohydrate metabolism variables. Based this findings, they suggested that the assessment of visfatin plasma levels can help to identify subjects with many metabolic abnormalities, which result in an increased cardiovascular disease risk.
Furthermore, Bessa et al. [30] assessed the correlation of visfatin with markers of endothelial dysfunction and inflammation in Egyptian patients with chronic kidney disease and concluded that; serum visfatin was strongly associated with endothelial adhesion molecules and considered as a non-traditional biomarker of endothelial dysfunction. Moreover, the relationship between this adipocytokine and C-reactive protein, interlukine-6, vascular and intercellular adhesion molecule-1 may reflect the sub-clinical inflammatory status. Thus, visfatin might be involved in the complex interaction between endothelial dysfunction, inflammation and atherosclerosis which result in increased cardio-vascular disease risk.

Vaspin modulated inflammation and postulated a suppressive influence on inflammatory process. Seeger et al. [31] found a negative relationship between vaspin and CRP in patients on chronic hemodialysis and Kadoglou et al. [19] found independent association of reduced vaspin with increased hsCRP and visfatin levels indicating a protective mechanism. On the other hand, visfatin was involved in the pro-inflammatory pathway of atherosclerosis development. It has been identified that visfatin, as an inflammatory mediator, localized to foam cell macrophages within unstable atherosclerotic lesions, that potentially plays a role in plaque destabilization [32]. Besides, visfatin can induce cellular expression of inflammatory cytokines such as tumor necrosis factor- $\alpha$, interlukine-1beta, and interlukine- 6 and correlation with hs-CRP and WBC which may reflect the inflammatory status and pro-atherogenic role of visfatin $[33,34]$.

\section{Limitations}

Some limitations should be considered before results interpretation. Our study was a cross-sectional study, not a randomized trial, and including a small number of patients. In addition, we did not follow up the patients enrolled in this study, which would introduce biases to data analysis and prevent us from establishing a cause-effect relationship of vaspin and visfatin with the presence and severity of CAD.

\section{Conclusions}

Patients with established stable CAD showed reduced vaspin and increased visfatin serum levels. Moreover, low vaspin and high visfatin levels were significantly correlated with CAD severity suggesting a link between atherosclerosis and adiposity. Therefore, vaspin and visfatin adipocytokines may used for prediction of CAD and estimation of its severity.

\section{REFERENCES}

[1] Sheridan SL, Viera AJ, Krantz MJ, Ice CL, Steinman LE, Peters KE, Kopin LA, Lungelow D: The effect of giving 
global coronary risk information to adults: a systematic review. Arch Intern Med 2010, 170(3):230-239.

[2] Finucane MM, Stevens GA, Cowan MJ, Danaei G, Lin JK, Paciorek CJ, Singh GM, Gutierrez HR, Lu Y, Bahalim AN, Farzadfar F, Riley LM, Ezzati M: National, regional, and global trends in body-mass index since 1980: systematic analysis of health examination surveys and epidemiological studies with 960 country-years and 9.1 million participants. Lancet 2011, 377(9765):557-567.

[3] Okay DM, Jackson PV, Marcinkiewicz M, Papino MN: Exercise and obesity. Prim Care 2009, 36(2):379-393.

[4] Gauvreau D, Villeneuve N, Deshaies Y, Cianflone K: Novel adipokines: links between obesity and atherosclerosis. Ann Endocrinol (Paris) 2011, 72(3):224-231.

[5] Lebovitz HE: The relationship of obesity to the metabolic syndrome. Int J Clin Pract Suppl 2003,134):18-27.

[6] Cheng KH, Chu CS, Lee KT, Lin TH, Hsieh CC, Chiu CC, Voon WC, Sheu SH, Lai WT: Adipocytokines and proinflammatory mediators from abdominal and epicardial adipose tissue in patients with coronary artery disease. Int $\mathbf{J}$ Obes (Lond) 2008, 32(2):268-274.

[7] Mazaherioun M, Hosseinzadeh-Attar MJ, Janani L, Vasheghani FA, Rezvan N, Karbaschian Z, Hossein-Nezhad A: Elevated serum visfatin levels in patients with acute myocardial infarction. Arch Iran Med 2012, 15(11):688-692.

[8] Fukuhara A, Matsuda M, Nishizawa M, Segawa K, Tanaka M, Kishimoto K, Matsuki Y, Murakami M, Ichisaka T, Murakami H, Watanabe E, Takagi T, Akiyoshi M, Ohtsubo T, Kihara S, Yamashita S, Makishima M, Funahashi T, Yamanaka S, Hiramatsu R, Matsuzawa Y, Shimomura I: Visfatin: a protein secreted by visceral fat that mimics the effects of insulin. Science 2005, 307(5708):426-430.

[9] Romacho T, Azcutia V, Vazquez-Bella M, Matesanz N, Cercas E, Nevado J, Carraro R, Rodriguez-Manas L, Sanchez-Ferrer CF, Peiro C: Extracellular $\mathrm{PBEF} / \mathrm{NAMPT} /$ visfatin activates pro-inflammatory signalling in human vascular smooth muscle cells through nicotinamide phosphoribosyltransferase activity. Diabetologia 2009, 52(11):2455-2463.

[10] Wang P, Vanhoutte PM, Miao CY: Visfatin and cardio-cerebro-vascular disease. J Cardiovasc Pharmacol 2012, 59(1):1-9.

[11] Hida K, Wada J, Eguchi J, Zhang H, Baba M, Seida A, Hashimoto I, Okada T, Yasuhara A, Nakatsuka A, Shikata K, Hourai S, Futami J, Watanabe E, Matsuki Y, Hiramatsu R, Akagi S, Makino H, Kanwar YS: Visceral adipose tissue-derived serine protease inhibitor: a unique insulin-sensitizing adipocytokine in obesity. Proc Natl Acad Sci U S A 2005, 102(30):10610-10615.

[12] Jung CH, Lee WJ, Hwang JY, Seol SM, Kim YM, Lee YL, Park JY: Vaspin protects vascular endothelial cells against free fatty acid-induced apoptosis through a phosphatidylinositol 3-kinase/Akt pathway. Biochem Biophys Res Commun 2011, 413(2):264-269.

[13] Phalitakul S, Okada M, Hara Y, Yamawaki H: Vaspin prevents TNF-alpha-induced intracellular adhesion molecule-1 via inhibiting reactive oxygen species-dependent NF-kappaB and PKCtheta activation in cultured rat vascular smooth muscle cells. Pharmacol Res 2011, 64(5):493-500.
[14] Reiber JHC: On-line quantification of coronary angiograms with DCI system. Medica Mundi 1989, 34(89-98.

[15] Gensini GG: A more meaningful scoring system for determining the severity of coronary heart disease. Am J Cardiol 1983, 51(3):606.

[16] Aust G, Richter O, Rohm S, Kerner C, Hauss J, Kloting N, Ruschke K, Kovacs P, Youn BS, Bluher M: Vaspin serum concentrations in patients with carotid stenosis. Atherosclerosis 2009, 204(1):262-266.

[17] Gandhi H, Upaganlawar A, Balaraman R: Adipocytokines: The pied pipers. J Pharmacol Pharmacother 2010, 1(1):9-17.

[18] El-Mesallamy HO, Kassem DH, El-Demerdash E, Amin AI: Vaspin and visfatin/Nampt are interesting interrelated adipokines playing a role in the pathogenesis of type 2 diabetes mellitus. Metabolism 2011, 60(1):63-70.

[19] Kadoglou NP, Gkontopoulos A, Kapelouzou A, Fotiadis G, Theofilogiannakos EK, Kottas G, Lampropoulos S: Serum levels of vaspin and visfatin in patients with coronary artery disease-Kozani study. Clin Chim Acta 2011, 412(1-2):48-52.

[20] Kobat MA, Celik A, Balin M, Altas Y, Baydas A, Bulut M, Aydin S, Dagli N, Yavuzkir MF, Ilhan S: The investigation of serum vaspin level in atherosclerotic coronary artery disease. J Clin Med Res 2012, 4(2):110-113.

[21] Li HL, Peng WH, Cui ST, Lei H, Wei YD, Li WM, Xu YW: Vaspin plasma concentrations and mRNA expressions in patients with stable and unstable angina pectoris. Clin Chem Lab Med 2011, 49(9):1547-1554.

[22] Zhang B, Peng W, Li H, Lu Y, Zhuang J, Wang K, Su Y, Xu $\mathrm{Y}$ : Plasma vaspin concentrations are decreased in acute coronary syndrome, but unchanged in patients without coronary lesions. Clin Biochem 2013, 46(15):1520-1525.

[23] Li HL, Zhang HL, Jian WX, Li Q, Peng WH, Xu YW: Association of vaspin gene polymorphisms with coronary artery disease in Chinese population and function study. Clin Chim Acta 2013, 415(233-238.

[24] Doran AC, Meller N, McNamara CA: Role of smooth muscle cells in the initiation and early progression of atherosclerosis. Arterioscler Thromb Vasc Biol 2008, 28(5):812-819.

[25] Phalitakul S, Okada M, Hara Y, Yamawaki H: A novel adipocytokine, vaspin inhibits platelet-derived growth factor-BB-induced migration of vascular smooth muscle cells. Biochem Biophys Res Commun 2012, 423(4):844-849.

[26] Fu H, Zhu Y, You GY, Liu XJ: [Detection of visfatin level of plasma in patients with coronary artery diseases]. Sichuan Da Xue Xue Bao Yi Xue Ban 2009, 40(2):322-324.

[27] Liu SW, Qiao SB, Yuan JS, Liu DQ: Association of plasma visfatin levels with inflammation, atherosclerosis and acute coronary syndromes (ACS) in humans. Clin Endocrinol (Oxf) 2009, 71(2):202-207.

[28] Cirillo P, Di P, V, Maresca F, Pacifico F, Ziviello F, Bevilacqua M, Trimarco B, Leonardi A, Chiariello M: The adipokine visfatin induces tissue factor expression in human coronary artery endothelial cells: another piece in the adipokines puzzle. Thromb Res 2012, 130(3):403-408.

[29] Filippatos TD, Tsimihodimos V, Derdemezis CS, Gazi IF, Saougos V, Mikhailidis DP, Tselepis AD, Elisaf MS: Increased plasma visfatin concentration is a marker of an 
atherogenic metabolic profile. Nutr Metab Cardiovasc Dis 2013, 23(4):330-336.

[30] Bessa SS, Hamdy SM, El-Sheikh RG: Serum visfatin as a non-traditional biomarker of endothelial dysfunction in chronic kidney disease: an Egyptian study. Eur J Intern Med 2010, 21(6):530-535.

[31] Seeger J, Ziegelmeier M, Bachmann A, Lossner U, Kratzsch J, Bluher M, Stumvoll M, Fasshauer M: Serum levels of the adipokine vaspin in relation to metabolic and renal parameters. J Clin Endocrinol Metab 2008, 93(1):247-251.

[32] Dahl TB, Yndestad A, Skjelland M, Oie E, Dahl A, Michelsen A, Damas JK, Tunheim SH, Ueland T, Smith C,
Bendz B, Tonstad S, Gullestad L, Froland SS, Krohg-Sorensen K, Russell D, Aukrust P, Halvorsen B: Increased expression of visfatin in macrophages of human unstable carotid and coronary atherosclerosis: possible role in inflammation and plaque destabilization. Circulation 2007, 115(8):972-980.

[33] Luk T, Malam Z, Marshall JC: Pre-B cell colony-enhancing factor (PBEF)/visfatin: a novel mediator of innate immunity. J Leukoc Biol 2008, 83(4):804-816.

[34] Oki K, Yamane K, Kamei N, Nojima H, Kohno N: Circulating visfatin level is correlated with inflammation, but not with insulin resistance. Clin Endocrinol (Oxf) 2007, 67(5):796-800. 